\title{
Trajetória anticapitalista no jovem Lukács: romantismo, religião e crítica da modernidade
}

\author{
Anti-capitalism trajectory in the young Lukács: \\ romanticism, religion and criticism to the modern way
}

\section{Fábio Py*}

Universidade Cândido Mendes (UCAM), Rio de Janeiro, RJ, Brasil

\section{Resumo}

Este trabalho apresenta, de maneira sintética, ponderações sobre os primeiros livros de Georg Lukács, pouco antes de sua adesão ao marxismo ortodoxo. A partir deles, visa-se reconhecer o esboço da trajetória anticapitalista na primeira etapa da vida do filósofo - chamada por Nicolas Tertulian de "a juventude de Lukács". Portanto, busca-se demostrar, no âmbito de sua juventude, suas descontinuidades à vida moderna por meio de pontos do romantismo e da religião. Assim, serão enfatizadas, nos anos de sua juventude, a partir dos livros publicados ainda na década de 1910, intituladas como "História da evolução do drama moderno", "A alma e as

\footnotetext{
FP: Doutor em Teologia, e-mail: pymurta@gmail.com
} 
formas" e "A teoria do romance", o traço do imagético religioso embebecido pelo romantismo nutrido pelo círculo dos intelectuais que se reuniam aos domingos na casa de Max Weber, em Heidelberg - o Círculo de Weber. Enfim, pretende-se com este artigo acentuar que, no centro da Europa, no início do século passado, construiu-se um novo leque de produção romântica crítica ao status quo religiosa, possibilitadora da renovação dos ares da produção intelectual europeia do início do século XX.

Palavras-chave: Georg Lukács. Romantismo. Drama e religião. Círculo de Weber.

\section{Abstract}

This work presents, in a synthetic way, considerations about first George Lukács books, right before his adhesion to orthodox marxism. From this books, this work seeks recognize the design of the anti-capitalist path in the first stage of philosopher's life - called by Nicolas Tertulian of "the youth of Lukács". Therefore, we seek to demonstrate, in the ambit of his youth, his discontinuities about modern life through matters of romanticism and religion. So, we will emphasize, in the years of the Lukács youth, from the books still published in the 1910s, named "History of the evolution of modern drama", "Soul and shapes" and "The Theory of Novel", the trace of religious imagery impregnated by the romanticism fed by the circle of intellectuals whohave meet at sundays, in Max Weber's house, in Heidelberg - The Weber's Circle. Finally, this work intents give an highlight in the fact that, in the center of Europe, at the beginning of last century, a new range of romantic production was build, that was critical to the status quo religious, giver of a renewal of the atmospheric of intellectual European production of the early twentieth century.

Keywords: Georg Lukács. Romanticism. Teatre and religion. Weber's Circle. 


\section{Introdução}

A obra de Georg Lukács, no seu todo, seria uma das fontes que ajudaram a configurar sua forma marxista distinta, mesmo estando, a partir de 1918, no epicentro político partidário comunista. Como destaca o especialista no chamado "Lukács maduro", Nicolas Tertulian (2008, p. 15-17; 2009, p. 76-79) ${ }^{1}$, Lukács tem mérito de trazer para a cena da politização do partido comunista europeu as referências da filosofia da história, entre as quais se destacam a retomada da importância da dialética e do conceito de história de Hegel. Algo que causou desconfiança e furor no centro do partido comunista entre os adversários marxistas ortodoxos e/ou pelo marxismo vulgar stalinista (LUKÁCS, 2003, p. 67; ARATO \& BREINES, 1986, p. 5-11; LÖWY, 1979, p. 134-145; GOLDMANN, 1959, p. 45-49).

O enfoque desse trabalho não é polemizar os debates entre Lukács e os signatários do comunismo marxista, mas sim, traçar o paralelo do esboço da juventude e as críticas primeiras anticapitalistas condensadas nos seus primeiros livros. Isso, porque a juventude de Lukács possibilitou um leque de acessos e formação para que, posteriormente, desenvolvesse uma filosofia marxista ${ }^{2}$ (TERTULIAN, 1971, p. 78-82; KONDER, 1978, p. 53-54). Para tanto, o centro deste trabalho se concentrará quando Lukács procurava produzir ensaios e livros a fim de concorrer à entrada na Universidade de Heidelberg, Alemanha. Ao que parece, nesse lócus, tem-se um lugar privilegiado do pensamento crítico, até mesmo do pouco explorado recorte religioso (e teológico), pois antes de sua entrada no "partidão", seus escritos condensavam um conjunto de correntes e vertentes indispostas com a civilização ocidental burgo-capitalista.

1 Como uma face alternativa, ao mesmo tempo de renovação do maxismo, Maurice Merleu-Ponty (2006, p. 11-19), admite sobre Lukács o início da corrente "marxismo ocidental”, um marxismo renovado europeu do século XX, que aos poucos vai se desvencilhando da carga do marxismo oficial, vulgar. Posteriormente isso foi utilizado por Perry Anderson (2008, p. 23-28), em Considerações sobre o marxismo ocidental. Outra análise sobre ele vem de Terry Eagleton (2011), Marxismo e crítica literária. Para um texto com sinalizações sobre o contexto do "marxismo ocidental", ver Domenico LOSURDO, Como nasceu e morreu o marxismo ocidental (2011, p. 56-58).

2 Para um texto sobre o maxismo e a literatura passando por Lukács, ver EAGLETON, 2011. 
Antes do "Lukács maduro" (marxista), sua produção da juventude tinha uma atitude romântica (ou neorromântica), expressa nas reuniões entre muros da casa de Max Weber, no Círculo de Heidelberg. Suas indisposições com a modernidade vinham sendo construídas desde seus estudos doutorais com Georg Simmel (MACEDO, 2009, p. 165), e, posteriormente, entre os anos de 1912-1918, ganham novas cores. Levando-o a chamar, nos últimos anos de vida, de um "romantismo anticapitalista": quando seus trabalhos versavam a estética e a arte. Assim, nos deteremos no jovem Lukács, pré-marxista, morador principalmente de Heidelberg, antes de retornar a Budapeste e adentrar ao partido comunista húngaro.

Nesse caso, buscaremos traçar sua inspiração religiosa do traçar político a partir de seu esboço da trajetória e, sobretudo, da evolução filosófica nesses anos a partir dos três livros publicados na década de 1910. São eles: 1) "História da evolução do drama moderno"; 2) "A alma e as Formas"; e 3) "A Teoria do Romance"3, obras as quais ressaltam um esboço de uma nova política (neorromântica) do início do século XX, uma forma comunista alternativa condensada na contrariedade ao modus civilizatório individual capitalista (PY, 2015, p. 112-156).

\section{"História da evolução do drama moderno": primeiras opções, influência de Georg Simmel e esboços anticapitalistas}

Georg Lukács nasce na Hungria, no dia 13 de abril de 1885, sendo o segundo filho de Adél Wertheimer e Jozséf Lukács - família de banqueiros de Budapeste. Desde o berço da infância, a tradição judaica não foi decisiva, mas sim a cultura alemã — o que se vê nos escritos, estudos e interesses pessoais (LÖWY, 2012a, p. 68-70; GOLDMANN, 1959, p. 46-48). Portanto, desde os primeiros rabiscos em sua formação, Lukács renega o universo burguês, por meio de um romantismo religioso, polemizando

3 Pela questão de espaço, fez-se o recorte entre as obras publicadas por Lukács na sua juventude, dado que, além dessas obras, se tem acesso a obras da juventude que foram publicadas posteriormente, como seus esboços que depois viraram livros: Dostojewski: Notizen und Entwürfe (1985), Heidelberger Philosophie der Kunst (1912-1914) (1974) e Estética (1966). 
desde a fundação do grupo Thalia Burhne. Esse grupo produz textos, peças, dramas e análises de obras entre os anos de 1904 e 1909, enquanto estudante da faculdade de letras em Budapeste. Participa ativamente da emergência do radicalismo intelectual húngaro, no qual entende o teatro como instrumento para promover a "subversão das consciências", alternativo ao status quo (VAISMANN, 2005, p. 67-94). Outro dado do período (1904-1909) marcante foi o primeiro casamento, com a russa Ielena Andreieievna Grabenko. Esposa responsável pelo conhecimento de Fiódor Dostoiévski, quando sussurrava as frases do literato russo na língua eslava, o que lhe possibilitou, posteriormente, inteirar-se e aprofundar seus conhecimentos no Círculo de Weber, a partir de 1912 (LÖWY, 2012b, p. 60-61) ${ }^{4}$.

Nesse primeiro momento ligado ao radicalismo húngaro, escreve o primeiro livro, o qual será conhecido como o mais sistêmico do jovem Lukács, intitulado História da evolução do drama moderno, de pretensões neokantianas, pelas influências de Georg Simmel, como admite na autobiografia (LUKÁCS, 1999, p. 36). O livro a História da evolução do drama moderno deve ser lido de seu lugar vivencial, isto é, da geografia húngara repleta de rumores de modos positivistas dos adversários de Budapeste. Assim, busca fazer uma interpretação das formas literárias à luz da sociologia da cultura (VAISMANN, 2005, p. 67-94), o preço do esforço de escrita da obra foi o prêmio que recebeu em 1908, em Budapeste. A obra receberá revisões até ser publicada, em 1912, abrindo o rol de escritos de Lukács, espalhando pelo centro europeu seu repertório queixas à civilização material burguesa. Por isso, sobre a juventude, Lukács (1999, p. 36) expressa como a "síntese da problemática da minha infância e da minha juventude: uma vida significativa no capitalismo, impossível; o combate para alcançá-la, tragédia”.

No conteúdo, o livro História da evolução do drama moderno apresenta as diferenças formais do drama antigo e o moderno: entendendo que o drama antigo vai da antiguidade ao século XVII, já, o moderno

4 Quem confirma isso é Ernst Bloch, indicando, inclusive, que Lukács foi o responsável por sua iniciação na literatura romântica russa. Ver a entrevista de Ernst Bloch para Michael Löwy (2012, p. 169-181), como apêndice de seu livro Judeus heterodoxos: messianismo, romantismo e utopia. 
teria se iniciado com Schiller, por exemplo (LUKÁCS, 1966, p. 67-70). O moderno drama fora permeado de força dramática, que o adjetiva efetivamente. $\mathrm{O}$ que não existia no drama antigo relacionado à (história) política, isto é, à visão de mundo da nobreza e dos reinados. No drama antigo, a moral está sobre as bases da teologia, pouco suscetível a relativização; nele, a dialética dramática não se coloca em movimentos que se opõem por razões morais. Seu imaginário romântico-teológico se mobiliza a partir do entendimento de que a via moderna desfalece os laços do passado comunitário, típica da utopia judaico-cristã (LÖWY, 2012b, p. 60-61). A ética é a matriz de suas ações; contudo, os personagens poderiam ir contra a moral, sendo por isso ligados a razões demoníacas, à expressão negativa da cultura religiosa (LUKÁCS, 1966, p. 225-234). O drama moderno seria resultado do projeto burguês, classe social que desde os seus inícios jamais gozou da insegurança, até porque os sentimentos, pensamentos, teologias e a valorização dos homens podem se modificar segundo a situação que lhes é posta (LUKÁCS, 1966, p. 267). O moderno, que está embelecido do imaginário burguês, seria o "primeiro nascido mediante um contraste consciente de classes" (LUKÁCS, 1966, p. 269) e Lukács acena seu olhar social como se existissem diferentes lutas de classes ocorrendo no interior da sociedade. As diferentes classes e projetos em conflito desempenham um papel decisivo na estrutura e na ação das características dos dramas logo nas aspirações religiosas destas, levando o moderno a passar pelos extratos sociais no tema. O jovem Lukács (1966, p. 267) percebe, a partir da forma moderna, que cada classe e grupo social retêm uma visão de mundo, então, ele se constrói na base de diferentes teologias e das diferentes visões de mundo que "põe em movimentos os homens e os opõe mutuamente" (LUKÁCS, 1966, p. 267). O que vai chamar de traço estilístico do drama moderno, uma "pluridimensionalidade no social" (LUKÁCS, 1966, p. 129).

Dito isso, o primeiro trabalho de Lukács tem em si o dado inovador da pluralidade de valores e expressões religiosas, que são fortuitamente espalhados nas folhas do drama moderno. Como ele mesmo salienta: a pluralidade de valores colidem no drama moderno, pois a "valoración que constituye el fundamento del drama y pone en orden el mundo, es aún completamente unitaria y burguesa” (LUKÁCS, 1966, p. 267). 
Por relacionar a estética, teologia e as condições econômicas da sociedade, Lukács (1966, p. 272) assume que as formas econômicas da classe burguesa dominavam "a vida inteira". Por isso, o seu primeiro trabalho escrito se coloca junto ao ramo da sociologia da literatura, estabelecendo relações explícitas e mecânicas entre as épocas, religiões e as formas artísticas, fazendo com que o drama moderno seja inseparável da classe burguesa: "El drama moderno es el drama de la burguesía; el drama moderno es el drama burgués” (LUKÁCS, 1966, p. 52). Generalizando sobre a modernidade, Lukács (1966, p. 272) afirma: “[...] cualquier drama es burgués, porque las formas de vida contemporáneas son burguesas y porque las formas de cualquier exteriorización de la vida actual están determinadas por sus formas".

Assim, na raiz metodológica da primeira obra escrita de Lukács existe a inspiração anticapitalista do livro de Georg Simmel a Filosofia do Dinheiro (1900), do qual retira o ponto do desagravo da preponderância da quantidade sobre a qualidade na modernidade, a dissolução de tudo o que for determinação específica, individual, qualitativa, pela simples determinação numérica. Fomenta que o caminho moderno é o da dominação cada vez mais esmagadora do dinheiro sobre a vida social e a religião; a saída para isso seria a busca da comunicação dos ramos socialistas e religiosos, algo implícito no livro, por isso, escreve:

O sistema do socialismo e sua visão de mundo, o marxismo, constituem uma síntese. A síntese mais impiedosa e mais rigorosa - talvez desde o catolicismo da Idade Média. Só poderá ser expressa, quando chegar o tempo de dar-lhe uma expressão artística, por uma forma tão severa e tão rigorosa quanto à arte autêntica deste último (penso em Giotto, em Dante), e não a arte puramente individual, impelindo individualismo até as nuanças mais extremas, produzidas pelos tempos atuais (LUKÁCS apud LÖWY, 2012b, p. 57) $)^{5}$.

5 Lucien Goldmann, em seu Le Dieu Caché, étudé sur la vision tragique dans les 'Pensés' (2008, p. 165-169), descreve que as visões de mundo em Lukács, religiosa e socialista, haviam em comum os fundamentos transindividuais. 
Portanto, já na primeira produção do jovem Lukács, a Kultur, a religião e o socialismo aparecem na visão de mundo como vasos comunicantes opostos ao ethos da sociedade burguesa. Sua contrariedade anti-burguesa está nos fundamentos de seu escrito, transparecendo nele tons da religião romântica, quando acena a própria essência da modernidade e do dinheiro como fruto da prostituição, da indiferença e a infidelidade que se separa de cada sujeito porque não se liga a outro qualquer.

\section{"A alma e as Formas" e a inserção de Lukács no Círculo de Heidelberg}

Se desde o momento em que Georg Lukács começa sua atividade acadêmica se vê nele ressalvas à modernidade, esse dado é ampliado quando se engaja no universo acadêmico de Heidelberg, desembarcando em maio de 1912 (MACEDO, 2009, p. 143-181). Vem à cidade universitária das proximidades da casa de Weber, informando que fazia opção por um socialismo que aproximava a fala de Deus e um coletivismo religioso. Tal contração que, nos escritos posteriores, vai chamar de "teologia" (LUKÁCS, 2009, p. 123-124) ou de "religião romântica" (LÖWY, 2012b, p. 57), quando praticava a negação total da sociedade burguesa moderna, individualista, como expressa para um amigo, antes da ida para a cidade: "[...] a única esperança poderia estar no proletariado, no socialismo [...] [mas] parece que o socialismo não tem o poder religioso de preencher toda alma; poder que caracteriza o cristianismo primitivo (LUKÁCS apud LÖWY, 2012b, p. 56-57)”.

Desembarca, socialista e religioso em Heidelberg, trazendo em suas mãos um segundo livro escrito, seu primeiro publicado em 1910, intitulado de "A alma e as formas". Obra bem recebida pelos intelectuais, mas sem sucesso entre os professores universitários. O que teria acarretado a mudança do jovem Lukács de Budapeste para Heidelberg sobre o convite de Ernst Bloch. Foi para Heidelberg para participar mais estreitamente da vida da cidade universitária, tendo acesso ao Círculo de Max Weber, com pretensões da bendita cátedra universitária 
em Heidelberg (LÖWY, 2012b, p. 166) ${ }^{6}$ — ou, o Pós-Doutoramento na universidade com Windelband ou Rickert. Vale lembrar que a Uni Heidelberg era uma universidade das mais importantes da Europa no início do século XX (TEIXEIRA, 2010, p. 211-217). Também, historicamente não se pode deixar de salientar que, na ida de Lukács para a cidade, defronta-se com o processo de industrialização bruto pelo qual passava a Alemanha - pouco vista na modernidade europeia (LÖWY, 2012b, p. 54). Ocasionando a distensão nos valores (mais) comunitários da Germânia, dessa forma, se compreende todo o trabalho fomentado pelo Círculo de Weber em Heidelberg, com sua efervescência romântico-religiosa (LÖWY, 2012b, p. 54).

A segunda obra escrita pelo jovem Lukács teve até boas repercussões, contudo nos setores intelectuais, como o próprio Max Weber e o amigo Ernst Lask, preocupam-se pelo caráter ensaístico da obra (MACEDO, 2009, p. 143-181). O livro reata a tradição da filosofia clássica ao definir significação pela relação entre a alma e o absoluto, todavia, situa a autenticidade na consciência dos limites e da morte, ele sustenta até o fim uma visão trágica que desemboca na recusa do mundo e de todas as formas inautênticas. Daí decorre uma nova forma de produzir literatura, no qual pede o afastamento da "cultura espiritual", reagindo como se "um tempo que não é favorável à poesia", isso porque a solidão do "homem arrancado de todos os laços sociais" (LUKÁCS, 1974 , p. 36), no qual ele busca a todo o momento seu pertencimento, de até o pertencimento religioso.

Opinando sobre a obra, Arlenice Almeida da Silva (2009, p. 5683) percebe que Lukács constrói a nova literatura, não como antes do interior, como Goethe, mas dialeticamente, "pois as determinações específicas (da poesia moderna) deveriam, se não me equivoco, vir do exterior, e as circunstâncias determinar o talento" (LUKÁCS, 1974, p. 136). Para Lukács (1974, p. 138-145), a novidade do lirismo no maduro Goethe consiste em demonstrar que, no mundo contemporâneo,

6 Para uma maior descrição do Circulo de Weber em Heidelberg, ver o recente livro de Michael Lowy (2013, p. 78-104), sobre Weber e o marxismo weberiano, que se chama La Cage d'Acier. Max Weber et Le marxisme wébérien. 
predomina cada vez mais um "estranhamento", por isso o desejo de pertencimento e comunhão só podia ser experimentado negativamente. $\mathrm{Na}$ modernidade, a proximidade tornou-se tão intensa, de modo que tudo parece passível de ser narrado. $\mathrm{O}$ que necessariamente não significa o acesso mais amplo ao que importa, o essencial. Ou seja, para o jovem Lukács (1974, p. 138-145), é diante da "mais absoluta proximidade que reside a mais terrível obscuridade”, quando na compreensão de tudo há a mais absoluta incompreensibilidade, resvalando-se na provisoriedade em relação ao Absoluto. Essa é a expressão maior da impossibilidade de conhecer o mundo das coisas, pois é pelo burburinho interminável no cruzamento dos sons que se preenchem os espaços e confundem-se os tempos. Por isso, a modernidade é confusa, entretanto, também é um espaço onde é possível uma saída, porque há nelas formas distintas de compreensões infinitas (LUKÁCS, 1974, p. 180).

Mesmo num livro mais ensaístico, o jovem Lukács (1974, p. 193197) segue traçando suas críticas à sociedade burguesa e sua conformação/habitual da "crise da cultura". Faz isso mediante o levantamento dos conceitos de vida, alma e forma no qual parecem coincidir uma concepção de uma razão trágica, religiosa da existência humana. Uma existência em que há por si mesma tanto como uma objetividade na vida como uma subjetividade alienada: sem forma, uma unidade sem sentido. O destino só pode ser evitado de maneira transitória, graças ao poder configurador e comunicativo da própria forma artística, com impossibilidade de um trato racional com a realidade que parece impor-se (LUKÁCS, 1974).

Lukács anuncia que a concepção de mundo burguês e reacionário segue sobre o relativismo e subjetivismo que ocultam o homem do progresso social lhe retirando a ação na sociedade, configurando uma religião pouco prática, "de liturgia vazia, sem dogma" como escreve Walter Benjamin anos depois (2014, p. 23-24). Portanto, com o livro A alma e as formas ele tem os primeiros contatos com Max Weber: trata de prometer uma obra mais acabada e não apenas um capítulo do que tinha submetido ao professor de Heidelberg e viria a ser sua Estética. Aliás, essa promessa de obra era a aposta de Weber para Lukács ter êxito na cátedra acadêmica, embora reconhecesse a dificuldade de terminá-la 
(TEIXEIRA, 2010, p. 211-217). Começou a escrevê-la no inverno de Florença, sobre os votos de Weber de ser o material de mais fôlego do jovem (MACEDO, 2009, p. 148-149).

Na eclosão da Primeira Guerra Mundial, Georg Lukács só tinha os três primeiros capítulos, e, em outubro de 1914, diminuiu os passos de sua Estética para poder se dedicar à sua filosofia da história a partir de Dostoiévski. O interesse vinha aumentando pelos encontros do Círculo de Weber, núcleo que se reunia debatendo a religião a partir dos místicos da idade média, do misticismo oriental e judeu, de Kierkegaard e, fundamentalmente, pelo russo Fiódor Dostoiévski (MACEDO, 2009, p. 149-150). O Círculo também estudava autores românticos como Novallis, Theodor Storm, Stefam George e Pául Ernst (LÖWY, 2012a, p. 66), encontravam-se aos domingos na casa e o filósofo para poder discutir entre os anos de 1908 - 1918 (WEBER, 1995, p. 593-594).

Outro detalhe: no Círculo de Weber discutiam-se temas ligados a atualidade; no entanto, o grosso da reflexão se ligava ao romantismo e a teologia pouco institucional, negando formas do capitalismo, principalmente pela dupla de romancistas russos, Léon Tolstoi e Fiódor Dostoiévski (LÖWY, 2012a, p. 67). Era um espaço de uma forma socialista branda, conectada às formas primitivas das religiões orientais, especialmente, ao cristianismo primitivo. Portanto, ele tinha apelo anti-burgues, antiliberal, contra o Estado constitucional, contra o parlamentarismo, o Iluminismo, o relativismo e o individualismo, normalmente pelo viés neo-romântico (LÖWY, 1979, p. 9-64). Por isso, o jovem Lukács se insere perfeitamente ao espírito do Círculo, sendo até, curiosamente ironizado por Emil Lask como um dos quatro evangelhos: Mateus, Marcos, Lukács e Bloch. Isso porque o jovem Lukács e seu amigo Bloch (LÖWY, 2012a, 67-74; 2013, p. 189-201), se preocupavam em conduzir críticas à sociedade moderna aprofundando na mística apocalíptica o messianismo de um novo reino de justiça nos tempos da Guerra Mundial (LÖWY, 2013, p. 127-148). 


\section{"A Teoria do Romance", guinada hegeliana e os tempos de guerra no Circulo de Heidelberg de Lukács}

Como se disse, com a modernização da Germânia, a cidade caminhou a passos largos em direção a trágica guerra. Dessa forma, pode-se dizer que as pretensões acadêmicas de Lukács, de se tornar um professor universitário, estavam em xeque pelo conflito. Por isso, o jovem (afobado) preocupa-se em produzir outro texto, que pudesse ser lido e avaliado pelos núcleos acadêmicos e professorais (LÖWY, 2013, p. 127-148). Na dinâmica do Círculo da casa de Weber, aproximou-se de Paul Ernst, Max Weber e Ernst Bloch. Vendo o aprofundamento da guerra pela Europa para a produção de sua Estética e separa seu primeiro capítulo como um livro. Obra que, inicialmente, será chamada de A Estética do Romance, posteriormente será batizada como a A teoria do romance. Texto arrematado em agosto de 1915, sendo o primeiro capítulo do livro de Dostoiévski, que ficara grande, como confirma a Paul Ernst (LÖWY, 2013, p. 127-148). Seu conteúdo era de uma filosofia da história, no qual seria, nas suas palavras, "uma introdução à apresentação histórico-filosófica da obra poética de Dostoiévski” (LUKÁCS apud LÖWY, 2013, p. 127-148).

O livro segue um caminho dos outros livros de Lukács: análises históricas dos romances e das expressões artísticas (LÖWY, 2012a, p. 134136; GOLDMANN, 1959, p. 9-15). Contudo, de fato, seria o trânsito do pensamento de Lukács dos neokantinianos para a filosofia da história de Hegel (SILVA, 2009, p. 78-79), sobre o pano de fundo de religião romântica composta da imagética cristã primitiva (LÖWY, 2013, p. 127-135). João Paulo Neto, no posfácio de A Teoria do Romance, propõe que ela seria fruto das "exigências morais radicalmente humanistas e antiburguesas, exacerbadas pelo barbarismo da guerra e com as suas contradições acentuadas pelo conhecimento da dialética hegeliana" (apud LUKÁCS, 2009, p. 238). Em A Teoria do Romance, Lukács (2009) preocupa-se em discutir as constituintes do romance: primeiro, a partir da filosofia das formas, depois, da epopéia, e, por fim, o significado histórico-filosófico do romance. Dentro das categorias que constrói, uma se destaca, a categoria de "romantismo da desilusão" (LUKÁCS, 2009), na qual: 
[...] sucede ao idealismo abstrato não apenas no tempo e na história, mas é também conceitualmente o seu herdeiro, o degrau seguinte, em termos históricos filosóficos, no utopismo a priori: naquele, o indivíduo, portador da exigência utópica à realidade, foi esmagado pela força bruta dessa última; nesse, essa derrota é o pressuposto da subjetividade [...] no Romantismo, o caráter literário de todo apriorismo em face da realidade torna-se consciente: o eu, destacado da transcendência, reconhece em si a fonte de todo o deve-se e - como conseqüência necessária - reconhece-se como o único material digno de sua realização. A vida faz-se criação literária, mas com isso o homem torna-se ao mesmo tempo o escritor de sua própria vida e o observador dessa vida como uma obra de arte criada (LUKÁCS, 2009, p. 123-124).

Na descrição do próprio jovem Lukács pode-se perceber a importância do romance à sua época, bem como a ideia de que ele se ligava à história traditiva própria, com dado de autenticidade. $\mathrm{O}$ que pode aferir-se nesse fragmento do jovem Lukács é a presença dos termos "utopia”, a "transcendência", que são firmes realidades que impregnam sua análise do romance, sendo até pedras de toque de sua religião social romântica (VAISMANN, 2005, p. 67-94). Outro dado é que faz sentido quando Michael Löwy (2012a, p. 68-70) diz que a mudança de tendências de Kant para Hegel, das primeiras obras do jovem Lukács para a última obra, ocorreu pela influência de Bloch - que apresentou Hegel a ele. O que deve ter desencadeado a reprovação de Weber e de Paul Ernst ao texto. Mesmo que justifiquem a reprovação (novamente) pelo seu caráter ensaístico, não condizendo com as características mais densas da academia (MACEDO, 2009, p. 169). Desaprovação vista na correspondência entre Weber e Lukács, quando cita Emil Lask:

Tenho de ser honesto com você e relatar-lhe o que um amigo muito próximo - Lask - disse de você: "ele nasceu um ensaísta e não persistirá no trabalho sistemático (profissional); ele não deveria, portanto candidatar-se à docência" [...] Com base no que você nos leu dos brilhantes capítulos introdutórios de sua Estética, discordo veemente dessa opinião. E como sua repentina inflexão para Dostoiévski pareceu dar respaldo a essa opinião, odiei e continuo odiar essa obra. Se realmente toma como fardo e uma frustração intoleráveis a necessidade de rematar uma obra sistemática antes de começar outra é com pesar que aconselho a desistir de qualquer pretensão à atividade docente (LUKÁCS, 1986, p. 264). 
Esta carta deve ter caído fundo no jovem Lukács. Voltando às tendências do jovem Lukács e A Teoria do Romance, Éva Karádi (1983, p. 9199) caracteriza que essa sua primeira fase de produção intelectual tem uma oscilação entre suas ações, as poucas sistematizações e os ensaios, entre a influência direta de Max Weber e Ernst Bloch, orbitando entre os compostos românticos e hegelianos. Confirmando o passo na direção hegeliana, Lukács (2009, p. 45) escreve que "as formas entrelaçam-se à realidade histórica, estão impregnados de historicidade; pertencem as etapas particulares de desenvolvimento humano". O comentarista Lee Congdon (1983, p. 93) acrescenta que Lukács não terminaria sua filosofia da arte, pois há, em A Teoria do Romance, uma reflexão de um "romantismo utópico com uma roupagem acadêmica". Contudo, é sabido que a fórmula de A Teoria do Romance é a expressão de Fichte, fruto da imersão na "era da perfeita pecaminosidade" (CONGDON, 1983, p. 15) - quando se pensa o livro produzido mediante ao contexto do misticismo apocalíptico de desfalecimento social, violências e de guerras. Guerra respaldada a partir do avanço da técnica, da individualização nos estados nacionais e tecnologias que transformou a maneira de se fazer batalhas (HOBSBAWN, 2009, p. 213-215). A condição, segundo Lukács, para o homem se livrar dos problemas e pecados, passa por perceber que o mundo terreno é o lugar onde age o mal e que além do mundo, na eternidade, encontra a utopia teológica (VAISMANN, 2005, p. 67-94). A ideia dele com a obra era que "o romance seja uma forma necessária da modernidade” (LUKÁCS, 2009, p. 118), no qual se configura pela característica da consciência da cisão, que se constata por ser incontornável pela necessidade da busca do sentido.

Da mesma forma, ressalta a descoberta de sua impossibilidade do imundo prosaico, pela presença viva do elemento demoníaco. A modernidade, para Lukács (2009, p. 10), vive um contínuo desabrigo da alma, por isso escreve: "o romance é uma construção 'problemática', emblema de uma modernidade que perdeu o sentido da vida". Assim, percebe Tolstói como desfecho do romance europeu, colocando o romance junto à epopéia, pois, "atribui ao mundo a ser configurado uma substancialidade que por mais mitigada que seja, ele de modo algum é capaz de suportar e manter em equilíbrio" (LUKÁCS, 2009, p. 156-159). 
Da situação transcendental moderna criou-se o romance na forma de uma épica possível, quando entende os romances de Dostoiévski como a superação do estilo, moldando um cristianismo ateu segundo Michael Löwy (2013, p. 127-135). Assim, a possibilidade de uma nova configuração do sentido junto ao mundo, em Dostoiévski, ocorre "entre ideal e realidade, entre ação e contemplação não há nenhum abismo, pois nele as idéias são sempre ação" (LUKÁCS, 2009, p. 160-161).

Por isso, no último capítulo de A Teoria do Romance, Lukács se detém nos escritores russos, Tolstoi e Dostoiévski e, principalmente, o último chama a atenção como um portador dessa religião ateísta: representada pelo personagem terrorista russo Iran Kaliayev. Lukács não estava preocupado com uma religião católica ou outra qualquer, institucionalizada, porém, com uma mística complexa e contraditória como a religião ateia (LÖWY, 2012b, p. 58-59). Fecha o capítulo de Tolstoi à Dostoiévski se despedindo da juventude com a esperança utópica na igualdade romântica, indivíduo e comunidade, conduzindo na pele desses escritores russos, profetas de uma nova harmonia, uma religião comunitária (LÖWY, 2012b, p. 71).

Por fim, em setembro de 1915, seu nome se encontra na lista dos convocados para participar, em Budapeste, da Primeira Guerra, no serviço militar. Volta à capital da Hungria, ficando lá por um ano, seguindo no contato por cartas com Weber. A ida para Budapeste torna-se um impedimento quando se pensa na sua candidatura à cátedra, além do livro A Teoria do Romance não ter caído nas graças dos professores universitários (como Weber e Emil Lask) — e somente entre os intelectuais como Thomas Mann?.

Em Budapeste redescobre os textos de Sorel e de Ervin Szabo. Em carta, lamenta ter publicado a obra, que seria apenas um capítulo ensaístico, como livro. Mas o faz, pois fazia ideia de que teria de ir para Guerra, tendo de passar um tempo nela. Em dezembro de 1918, filia-se ao Partido Comunista Húngaro, quando supera as dificuldades com o bolchevismo, passando a ler Marx como texto universal, mesmo lendo e refletindo-o com Szabo, Hegel e Dostoiévski. Assim, até aqui, os

7 Detalhe observado em Lukács (1986, p. 264-268; 1999, p. 36-41) e Macedo (2009, p. 169-171). 
estudiosos dividem o que é nomeado de "jovem Lukács” (LÖWY, 2012a, p. 68-70), isto é, até seus 33-34 anos, quando deixa de lado (um pouco) a tendência "romântica anticapitalista" (LÖWY, 2012a, p. 134-136; GOLDMANN, 1959, p. 9).

\section{Considerações finais}

Após esboçar a trajetória do jovem pensador húngaro Georg Lukács e sua atitude de inserção acadêmica, com a negação do modus de vida moderna pela teoria estética, gostaria de destacar que essa atitude é um campo aberto a ser somado para os estudos acadêmicos das formas religiosas mais afiadas à gauche do campo político. No período de 1912 até 1918, na juventude de Lukács, refletiu sobre a composição da literatura, das artes, da estética enquanto objeto científico. Como se indicou, os seus três livros publicados versaram sobre o romantismo, cujos objetos foram analisados sobre o pano de fundo das noções da filosofia de Georg Simmel, Max Weber e, finalmente, na obra final do jovem Lukács (A Teoria do Romance), a partir de Hegel. Quando diante do horror da Grande Guerra Mundial, se deixa acentuar, pelo contexto, a história das formas românticas, acentuando uma mística religiosa. Sobre a época, Leandro Konder aprecia da seguinte forma a produção do intelectual húngaro:

Já na sua primeira tentativa de elaboração de uma estética sistemática, em textos redigidos de 1912 a 1918, Lukács discutia a relação da criação artística com a realidade social objetiva em que se movem os artistas e assumia uma posição muito crítica em face ao naturalismo e em face da capitulação da subjetividade criadora artística à tirania da realidade objetiva externa. Nos escritos daqueles anos, o filósofo húngaro sustentava que o valor intrínseco da forma levava o artista a ir necessariamente além da representação naturalista dos objetos, desafiando-o a lidar de algum modo com a unidade do real (KONDER, 1996, p. 27).

Leandro Konder enfoca a época de sua produção sobre as formas literárias no tempo e, tomando sua última obra como parâmetro, deixa 
explícitas as formas literárias, além de produzir uma forma (literária) que expressa o posicionamento do homem diante da história, embevecido pela mística não-estrutural. Assim, pode ser compreendido o romantismo engajado do jovem Lukács, pois deixa de ser apenas um gênero literário, funcionando como um posicionamento social. Um transbordamento de escrita, literatura que se solidifica como ethos social, logo com expressões enraizadas na cultura teológica da época. É o que ele mostra a partir de autores como Tolstoi e Dostoiévski que, para Lukács (2009, p. 16), constroem uma completa negação da modernidade capitalista por meio de um cristianismo russo não institucional. Fazendo-se como um modus de vida no qual o Lukács maduro chamará de "romantismo anticapitalista":

A base sociológica de tais teorias é a atitude ambiente, tanto em termos filosóficos quanto políticos, do anticapitalismo romântico. Originalmente - no jovem Carlyle ou em Cobbert, por exemplo - trata-se de uma verdadeira critica do horror e da hostilidade cultural do capitalismo nascente, e por vezes, até de uma forma embrionária de crítica socialista, como no Past and Present de Carlyle (LUKÁCS, 2009, p. 16, grifo meu).

Quem incrementa essa indicação é Michael Löwy, preocupado em descrever a atitude política de Lukács. Löwy (2012b, p. 54) indica que o "romantismo anticapitalista" englobaria atitudes normalmente dissonantes, como o retorno à religião do passado, contestação do racionalismo moderno, crítica ao industrialismo urbano e quantificação dos relacionamentos sociais. Dessa maneira, embora a negação da modernidade estivesse presente desde o primeiro livro, A Teoria do Romance é o ponto alto de sua juventude, sobretudo, incrementado pelo viés histórico hegeliano. Entre os quais, nas palavras do maduro Lukács (no ano de 1963, quando escreve o prefácio de A Teoria do Romance), confeccionam uma crítica embrionária socialista-religiosa - sem referencial marxista direto. 


\section{Referências}

ANDERSON, P. Considerações sobre o marxismo ocidental. São Paulo: Boitempo Editorial, 2008.

ARATO, A.; BREINES, P. El jóven Lukács e los orígenes del marxismo occidental. México: Fondo de Cultura Economico, 1986.

BENJAMIN, W. O capitalismo como religião. São Paulo: Bointempo Editorial, 2013.

CARLI, R. Dois lados da mesma moeda: a dissolução da economia clássica e o nascimento da sociologia. In: Emancitação, Ponta Grossa, UEPG, 2009. p. 3-11.

CONGDON, L. The Young Lukács. North Carolina: The University of North Carolina Press, 1983.

EAGLETON, T. Marxismo e crítica literária. São Paulo: Unesp, 2011.

GOLDMANN, L. Le Dieu Caché: étudé sur la vision tragique dans les "Pensés". Paris: Gallimand, 2008.

GOLDMANN, L. Recherches dialectiques. Paris: Gallimard, 1959.

HOBSBAWN, E. A era do capital. São Paulo: Companhia das Letras, 2009.

KARÁDI, É. Ernst Bloch and Georg Lukács in Max Weber's Heidelberg. In: MOMMSEN, W.; OSTERHAMMEL, J. (Eds.). Max Weber and his contemporaries. London: Unwin Hyman, 1983. p. 499-514.

KONDER, L. Estética e política cultural. In: ANTUNES, R.; REGO, W. (orgs.). Lukács: um galileu no século XX. São Paulo: Boitempo Editorial, 1996. p. 27-35.

KONDER, L. Lukács e a arquitetura. In: Módulo, n. 45, 1978.

LOSURDO, D. Como nasceu e morreu o marxismo ocidental. Estudos de Sociologia, Araraquara, v. 16, n. 30, p. 213-242, 2011.

LÖWY, M. Para uma Sociologia dos Intelectuais Revolucionários. São Paulo: Ciências Humanas, 1979.

LÖWY, M. La Cage d'Acier: Max Weber et Le marxisme wébérien. Paris: Stock, 2013. 
LÖWY, M. Judeus heterodoxos: messianismo, romantismo e utopia. São Paulo: Perspectiva, 2012a.

LÖWY, M. Romantismo e messianismo. São Paulo: Perspectiva, 2012b.

LÖWY, M. Revolta e melancolia. São Paulo: Boitempo Editorial, 2015.

LUKÁCS, G. A teoria do romance. São Paulo: Editora 34, 2009.

LUKÁCS, G. Aportaciones a la historia de la estética. México: Grijalbo, 1966.

LUKÁCS, G. Dostojewski: Notizen und Entwürfe. Budapest: Akadémiai Kiadó, 1985.

LUKÁCS, G. Heidelberger Philosophie der Kunst (1912-1914). Darmstadt: Luchterhand, 1974.

LUKÁCS, G. História e consciência de classe. Estudos da dialética marxista. São Paulo: Martins Fontes, 2003.

LUKÁCS, G. L'âme et les formes. Paris: Gallimard, 1974.

LUKÁCS, G. Selected Correspondence 1902-1920. Nova York: Columbia University Press, 1986.

LUKÁCS, G. Pensamento vivido: autobiografia em diálogo. Viçosa: Editora UFV, 1999.

MACEDO, J. M. M. de. Posfácio do tradutor. In: LUKÁCS, G. A teoria do romance. São Paulo: Editora Duas Cidades/Editoria 34, 2009. p. 143-181.

MERLEAU-PONTY, M. As aventuras da Dialética. São Paulo: Martins Fontes, 2006.

SILVA, A. A. O lirismo em Gyorgy Lukács. In: Kriterion, Belo Horizonte, v. 50, n. 119, p. 56-83, 2009.

PY, F. Lauro Bretones: um protestante heterodoxo no Brasil de 1948 à 1956. 2015. 246p. Tese (Doutorado em Teologia) - Pontifícia Universidade Católica do Rio de Janeiro, Rio de Janeiro, 2015. 
TEIXEIRA, M. O. N. Considerações Bibliográfico sobre um dialogo vivo: Georg Lukács e Max Weber em Heidelberg do início do século XX. In: Ideias, Campinas, n. $1,2^{\circ}$ semestre, 2010. p. 3-23.

TERTULIAN, N. Georges Lukács. Testament politique. Cité, n. 39, Paris, p. 34-39, 2009.

TERTULIAN, N. L'évolution de la pensée de Georg Lukács. In: L'Homme et la Societé, Paris: Editions Anthropos, n. 20, avril-mai-juin/1971.

TERTULIAN, N. Georg Lukács: etapas de seu pensamento estético. São Paulo: Editora Unesp, 2008.

VAISMANN, E. O jovem Lukács: trágico, utópico e romântico? In: Kriterion: Revista de Filosofia, Belo Horizonte, v. 46, n.112, 2005. p. 67-94.

WEBER, M. Biografia de Max Weber. México: Fondo de Cultura Económica, 1995.

Recebido: 21/11/2015

Received: 11/21/2015

Aprovado: 30/06/2016 Approved: 06/30/2016 